\title{
Immersion and Submersion Classrooms: A Comparison of Instructional Practices in Language Arts
}

\author{
Lucy Fazio and Roy Lyster
}

McGill University, Montreal, Canada

Using the Communicative Orientation of Language Teaching (COLT) observation scheme (Spada \& Fröhlich, 1995), this study compares the second language (L2) learning environments of elementary-level students of French in four submersion and four immersion classrooms in the Montreal area. The database is composed of almost 60 hours of observations during language arts lessons: 28.4 hours in the four submersion classrooms, so named because they are designed for native speakers of French but comprise a large number of minority-language students obliged to attend French-language schools, and 30.5 hours in the four French immersion classrooms, composed of a majority of anglophone students attending English-language schools. Results indicate clear differences between the two environments. Language arts lessons in the four submersion classrooms are predominantly analytic; the content focus is primarily on language form and most materials entail only minimal discourse. Conversely, language arts lessons in the four immersion classrooms involve a more balanced combination of analytic and experiential orientations, including more variety in classroom organisation, content that focuses on both language and other topics, and text that includes more extended discourse.

\section{Introduction}

This paper describes a process-oriented study that compares the second language (L2) learning environments of four immersion and four submersion classrooms in the light of instructional practices and procedures observed in almost 60 hours of language arts lessons. Although immersion and submersion programmes share the surface feature of providing instruction to learners through the medium of an L2, they are distinct in various ways. From several sources (Leung \& Franson, 1989; Skutnabb-Kangas, 1991; Swain \& Johnson, 1997), a summary can be compiled of at least three core characteristics that are known to distinguish typical immersion and submersion programmes.

First, typical immersion programmes are conducive to the development of additive bilingualism; that is, they aim to enhance the language repertoire of learners who, upon completion of their studies, achieve high proficiency in their L2 and record first-language (L1) performance comparable to that of peers who have received instruction through their L1. Conversely, in submersion contexts, learners are apt to experience subtractive or 'replacive' (Swain \& Johnson, 1997) bilingualism insofar as they become proficient in their L2 but at the expense of their L1, which may be undervalued in the educational milieu.

Second, there are differences concerning the languages spoken by educators in the two settings. Teachers participating in immersion programmes are usually bilingual, or minimally understand their pupils' mother tongue, a factor that may facilitate communication, particularly in the initial phases of learning. Submer- 
sion teachers in multilingual classrooms are not likely to know the various mother tongues spoken by their students and are not in a position, therefore, to offer parallel communicative support. In addition to its value in scaffolding communication, educators' knowledge of their pupils' L1 can be a source of emotional security for L2 learners.

Third, because immersion students usually have the same L1 and possess similar levels of L2 proficiency upon entry into L2 programmes specially designed to meet their learning needs, they compete on a more or less equal footing in the formal evaluation process. This is not the case in submersion programmes where the progress of the L2 learners is compared with the progress made by native speakers in the same classroom.

In addition to these distinguishing characteristics, what can be said of differences in the overall orientation of language teaching in immersion and submersion classrooms? In both contexts, do language arts lessons provide L2 learners with relevant opportunities for L2 learning in accordance with theoretically motivated proposals for communicative language teaching and programme design? In one such proposal, for example, Stern $(1990,1992)$ maintains that optimal conditions for L2 learning obtain when analytic and experiential approaches to L2 teaching are considered complementary, rather than mutually exclusive to one another, and are combined at the level of programme activity.

Stern describes the analytic teaching strategy as one that attends to the structural and functional properties of language and involves the study of discrete language items; pays attention to accurate, error-free production; is concerned with speech acts, discourse rules and sociolinguistics; and entails practice or rehearsal of specific language skills. On the other hand, the experiential teaching strategy focuses on content (subject-matter, themes and topics of interest) rather than language per se, and therefore emphasises fluency and the meaning of the message being communicated. In addition, learners are not asked to practise or rehearse language; they interact socially and engage in purposeful language tasks and projects. However, Stern depicts these two approaches along a continuum rather than dichotomously, and recommends pedagogical intervention in cases where programmes of instruction are strongly skewed in either direction of the continuum. Thus, programmes that are mainly experiential would benefit from the inclusion of analytic strategies at the level of classroom activity and those that are mainly analytic in their approach would be well served pedagogically by the integration of components of the experiential strategy.

In this paper, we draw on Stern's concept of the analytic-experiential continuum to compare and contrast the $\mathrm{L} 2$ learning environments of submersion and immersion classrooms in the Montreal area of Quebec, Canada. In this context, young learners of French L2 receive their formal schooling in one of two ways: (1) in French-language schools where French is the dominant language used by administrators, teachers, and students (submersion context); or (2) in English-language schools where English prevails (immersion context). Eligibility for attending French-language schools and English-language schools is governed by Quebec's language law (Bill 101) and is determined by numerous criteria, including the learner's L1 background. With few exceptions, minority-language 
children, who by definition speak a mother tongue other than French or English, are obliged to attend French-language schools where they are integrated into classes intended for native speakers of French, thereby creating for them a context of submersion education. These classrooms are culturally and linguistically diverse (Fazio, 1994). In contrast, the vast majority of children whose L1 is English may choose to learn French in a programme of immersion. French immersion programmes are offered within English-language schools where the goal is to teach subject-matter content through the medium of the French language to a more homogeneous group of L2 learners. In both settings, whether the L2 learners receive instruction in a submersion or an immersion classroom, the shared goal is to become proficient in French L2.

\section{Research Question}

The present study compares four immersion and four submersion classrooms in the Montreal area with respect to the overall communicative orientation observed in language arts lessons. The aim is to locate the eight elementary-level classrooms along the analytic-experiential continuum, then to determine the extent to which the notion of complementarity of pedagogical orientations is reflected in the target contexts. The comparison hinges on the use of a research instrument that was specifically designed to capture differences between a more analytic and a more communicative/experiential orientation in L2 pedagogy: namely, the Communicative Orientation of Language Teaching (COLT ) observation scheme (Spada \& Fröhlich, 1995). The specific research question is:

What are the similarities and differences in the type of language arts instruction received by L2 learners of French in the submersion context of the French-language schools and the immersion context of the English-language schools?

To date, this comparison has not been made. Whereas the COLT scheme has been used in immersion classrooms to determine overall communicative orientation (Allen et al., 1990), as well as how this orientation varies in relation to programme type (Dicks, 1992), parallel research has not been undertaken with respect to submersion classrooms (see Spada \& Fröhlich, 1995, for a detailed review of studies using COLT in a variety of other classroom contexts).

\section{Method}

\section{Research context and participants}

We examine a total of eight classrooms, four from the submersion context and four from the immersion context. The four submersion classrooms (S1, S2, S3 and S4) are all at the Grade 5 level and they are located in two French-language schools. The four French immersion classrooms (I5, I6, I7 and I8) are at the Grade 4 level (including one 'split' Grade 4/5) and they are situated in four different English-language schools. On average, there are 28 learners per submersion classroom and 26 learners per immersion classroom, for a total sample size of 216. 


\section{Submersion context}

Upon entering the French-language school system, minority-language students are first placed in a sheltered welcoming class (conducted exclusively in French) for a maximum period of 10 months. Subsequent placement in the mainstream classrooms represented in our sample by S1, S2, S3 and S4 is contingent on enrolment demands in the welcoming class and on learner proficiency in oral and written French.

Students in classroom S1 receive all their instruction in the French language, with the exception of two 60-minute periods of ESL instruction per week; students in classrooms S2, S3 and S4 (located in the same school) also receive all their instruction in the French language, except for two 45-minute periods of ESL instruction each week.

Classrooms S1, S2, S3 and S4 vary with respect to the percentage of minority-language students found in each. In S1, 50\% of the students are minority-language students and their mother tongues include Arabic, Farsi, Khmer, Thai, Hindi, English and Chinese. In S2, 34\% of the class consists of minority children whose first language may be Punjabi, Portuguese, English, Arabic, Chinese or Creole; in S3, 38\% of the learners are of a minority-language background and the mother tongues they speak include Arabic, English, Italian, Portuguese, Romanian, Somali, Polish, Spanish and Chinese. In S4, 43\% of the class consists of minority children and counted among their first languages are Portuguese, Lingala (a variety spoken in Zaire), Spanish, English, Chinese, Arabic, Polish and Farsi. No single mother tongue predominates in any of these four classrooms, where the remainder of the learners are francophones. (Note that English is the mother tongue of a small number of minority-language students; this is because, under Bill 101, some children whose L1 is English do not qualify for English-language schools and they therefore become L2 learners in French-language schools.)

\section{French immersion context}

The four French immersion classrooms, I5, I6, I7 and I8, are located in four different suburban English-language schools. Classroom I5 is in a school that offers an early total immersion programme where the students' school day, since Grade 1, has been entirely in French except for about one hour of English. The home languages of the students in I5 vary: 12 speak English at home, 6 speak French, 4 Arabic, 3 Chinese, 3 Spanish, 1 Greek, and 1 Polish. In contrast, I6, I7 and $\mathrm{I} 8$ are in schools that offer a middle immersion programme beginning in Grade 4. Prior to Grade 4, the students' school day was in English except for a one-hour French lesson. In Grade 4 (and 5), the students' day is about $60 \%$ in French (including science, social studies, maths and French language arts) and $40 \%$ in English (physical education, moral education, music and English language arts). The students in I6, I7, and I8 come primarily from Englishlanguage homes.

\section{Observation instrument}

COLT consists of two parts: Part A describes classroom activities at a macro-level as it focuses on organisational and pedagogical aspects of the observed events; Part B examines, at a more micro-level, the verbal interactions 
that take place within these activities. Each part is subdivided into several categories or features whose occurrence is coded in 'real-time' during classroom observations for Part A, and post-hoc from classroom audiotapes and transcriptions in the case of Part B (see Allen et al., 1984, and Fröhlich et al., 1985, for descriptions of the development and validation of the COLT scheme). It is not necessary, however, to use both Parts A and B of the COLT scheme. Because the present study compares immersion and submersion classrooms with respect to overall communicative orientation and not with respect to specific features of teacher-student interaction, only Part A of the COLT scheme is used. Part A allows for each observed pedagogical activity (the basic unit of analysis) to be coded along five main categories: participant organisation, content, content control, student modality and materials type.

The first main category, 'Participant organisation', characterises the way in which students are organised during a given activity. Three broad arrangements are possible: students may be working as a whole class; they may be divided into groups; or they may be engaged in individual seat work. A further breakdown permits the coder to indicate whether, when the learners are organised in groups or individually, they are working on the same or different tasks, and when organised as a whole class, whether the teacher or the student(s) is leading the activity. Group participant organisations where students are more likely to be initiating discourse, negotiating meaning and developing their fluency skills, tend to align closely with the experiential strategy. Whole class and individual participant organisations which generally offer less opportunity for active communication among students are considered to be more analytic in nature.

The second main category deals with the 'content' of the classroom activities. Here, the observer differentiates among four possible subcategories: classroom management, which deals with either procedural directives or disciplinary statements; instruction concerned exclusively or primarily with language, be it a focus on form (including grammar, vocabulary, and pronunciation), function, discourse or sociolinguistics; other topics, which refers to meaning-oriented, subject-matter and thematically-based instruction; or a combination option in which activities integrate equally a focus on aspects of language code and a focus on other topics. When content deals exclusively with components of the language subcategory, an analytic strategy is indicated and when it exclusively addresses aspects consonant with the other-topics subcategory, an experiential strategy is reflected. The combinations subcategory also tends to reflect an experiential orientation insofar as focus on form and focus on meaning are integrated. Management, of course, is not part of the planned curriculum content; however, to the extent that procedural and disciplinary directives are naturally occurring classroom phenomena that fall within the range of authentic communication, this subcategory is also said to be suggestive of the experiential strategy.

In the third category of the scheme, 'content control', a distinction must be made about who is controlling the content of the observed activity. Is it the teacher and the text, is it the student(s) alone, or is it a collaborative effort involving the teacher, the text and the student(s)? An experiential strategy is suggested in those instances when students are engaged to some degree as joint negotiators of the 
pedagogical process and play some part in decisions regarding content. Thus, absence of student input is considered more in line with an analytic approach.

The fourth main category refers to 'student modality' and it focuses attention on whether the students are listening, speaking, reading or writing in isolation, which is generally indicative of analytic teaching, or whether these skills are occurring in combinations which would reflect a more authentic, more experiential use of language.

The fifth main category allows for a judgment to be made about 'materials type', specifically the nature of the text that learners are exposed to. Minimal text refers to isolated sentences, word lists, fill-in-the-blank activities, etc., all of which tend to align more closely with an analytic approach. On the other hand, paragraphs, dialogues and whole stories are all examples of extended text which usually accompanies an experiential orientation in pedagogy. Some activities may call for the simultaneous and equal use of minimal and extended texts (e.g. the learner is asked to read a story and complete a fill-in-the-blank task consisting of isolated sentences designed to test for reading comprehension). The final subcategory is labelled other and is intended to account for those occasions when the teacher uses the blackboard or other audio and/or visual materials, as well as occasions when no materials are in use, such as during oral discussions or during some procedural and all disciplinary directives.

\section{Procedure and analysis}

The COLT data derive from a total of 3531 minutes ( 58.9 hours) of observation time spread across the eight classrooms: 1704 minutes (28.4 hours) are from the submersion context; 1827 minutes ( 30.5 hours) are from the French immersion context. One of the investigators carried out all the observations ( 24 in total) in the submersion classes and these sessions were always during periods of French language arts. In addition to coding for COLT in the classroom, she also took extensive field jottings which have since been transformed into formal fieldnotes (reported in Fazio, in progress).

Across the immersion classrooms, there was a total of 29 observations carried out by different observers on different occasions. During the observation sessions, observers coded for COLT while tape-recordings of the classroom events were produced (analyses of which appear in Lyster, 1998a,b,c; Lyster \& Ranta, 1997). Observations were made during a variety of lessons in the French immersion context but, for the purpose of our comparison, the 1827 minutes which contribute to the database were selected post-hoc for inclusion in this study because they were deemed to have a French language arts focus. By excluding subject-matter lessons in the immersion classrooms, the analysis of the eight classrooms takes account of language arts lessons only.

COLT raw data consist of coding sheets which indicate the occurrence of specific features with check marks in the appropriate categories; analysis of the data involves the calculation of percentage of total time devoted to each feature. It is the relative overall occurrence and non-occurrence of features that allows for the characterisation of a particular learning environment as being more communicative/experiential or more analytic in its orientation. 


\section{Results}

In this section, we present the quantitative results of the COLT analyses, followed by profiles of the two different L2 learning environments distinguished by the COLT scheme, which are then supported by descriptions extracted from our qualitative data. As recommended by Spada and Fröhlich (1995), the procedure followed for analysis of the COLT data is the calculation of the percentage of total time attributable to each of the categories and subcategories of the scheme. We present these quantitative results for each class in tabular form. Due to the similarities that became apparent in the four submersion classes, and how they compared with similarities across the four immersion classes, an average for the submersion group as a whole and for the immersion group as a whole is also presented in the tables.

Results pertaining to the category of 'participant organisation' in all eight classes are presented in Table 1 . On average, the submersion classes spent $81 \%$ of their time engaged in whole-class activities, including $78 \%$ in teacher-led activities and only 3\% in student-led activities. The remaining $19 \%$ of their time was devoted to individual seat work. No group work occurred during observations in any of the submersion classes. In comparison, $16 \%$ of the time in immersion classes was devoted to group work. Immersion students were engaged in individual seat work $14 \%$ of the total time and were organised in whole-class activities during the remaining $70 \%$ of the their class time, $8 \%$ of which included student-led activities.

Table 1 Participant organisation (\% of total time for each class and average [AV.] for submersion group and for immersion group)

\begin{tabular}{|l|rrrrrrrrrrr||}
\hline & $S 1$ & $S 2$ & $S 3$ & $S 4$ & $A V$. & $I 5$ & $I 6$ & $I 7$ & $I 8$ & $A V$. \\
\hline Class & & & & & & & & & & \\
\hline Teacher-led & 67 & 83 & 79 & 84 & 78 & 89 & 60 & 40 & 60 & 62 \\
\hline Student-led & 0 & 0 & 5 & 6 & 3 & 0 & 25 & 6 & 2 & 8 \\
\hline Individual & & & & & & & & & & \\
\hline Same & 29 & 13 & 16 & 10 & 17 & 8 & 11 & 11 & 28 & 14 \\
\hline Different & 4 & 4 & 0 & 0 & 2 & 0 & 0 & 1 & 1 & 0 \\
\hline Group & & & & & & & & & & \\
\hline Same & 0 & 0 & 0 & 0 & 0 & 3 & 4 & 31 & 9 & 13 \\
\hline Different & 0 & 0 & 0 & 0 & 0 & 0 & 0 & 11 & 0 & 3 \\
\hline
\end{tabular}

The percentage of time in each class devoted to the various categories of 'content' is displayed in Table 2. The results reveal clear differences between the two groups. First, submersion classes spent only $1 \%$ of their time on content related to classroom management whereas $10 \%$ of the total time in immersion classes was spent on management. Second, $77 \%$ of the time in submersion classes entailed an exclusive focus on language (including $76 \%$ on form and $1 \%$ on discourse) while only $32 \%$ of the time in immersion classes was attributable to an exclusive language focus ( $25 \%$ on form, $6 \%$ on discourse, and $1 \%$ on language function). Third, other topics were the main content focus during only $12 \%$ of the time in submersion classes compared to $37 \%$ of the time in immersion classes. Finally, combinations of a focus on language and other topics occurred $10 \%$ of the time in submersion classes and $21 \%$ of the time in immersion classes. 
Table 2 Content (\% of total time for each class and average [AV.] for submersion group and for immersion group)

\begin{tabular}{||l|rrrrr|rrrrr|}
\hline & $S 1$ & $S 2$ & $S 3$ & $S 4$ & $A V$. & $I 5$ & $I 6$ & $I 7$ & $I 8$ & $A V$. \\
\hline Management & 0 & 1 & 1 & 1 & 1 & 7 & 20 & 9 & 7 & 10 \\
\hline Language & & & & & & & & & & \\
\hline Form & 80 & 73 & 78 & 73 & 76 & 32 & 20 & 11 & 40 & 25 \\
\hline Function & 0 & 0 & 0 & 0 & 0 & 0 & 0 & 3 & 0 & 1 \\
\hline Discourse & 2 & 0 & 0 & 0 & 1 & 1 & 0 & 12 & 0 & 6 \\
\hline Sociolinguistics & 0 & 0 & 0 & 0 & 0 & 0 & 0 & 0 & 0 & 0 \\
\hline Other topics & 0 & 11 & 12 & 24 & 12 & 42 & 32 & 47 & 21 & 37 \\
\hline Combinations & 18 & 15 & 9 & 2 & 10 & 18 & 28 & 18 & 22 & 21 \\
\hline
\end{tabular}

The category of 'content control' did not discriminate between the two groups. As displayed in Table 3, the teacher and/or the text determined the content $89 \%$ of the time in submersion classes and $83 \%$ of the time in immersion classes. Students collaborated in content control, along with teacher and text, $11 \%$ of the time in submersion classes and $17 \%$ in immersion classes. In none of the eight classes were there any instances coded wherein students were able to determine independently the content. It is interesting to note that in other studies using COLT with young learners (e.g. Yohay \& Suwa, reported in Spada \& Fröhlich, 1995: 151), this category was not examined because it was anticipated that young learners would exert no control over the selection of topics.

Table 3 Content control ( $\%$ of total time for each class and average [AV.] for submersion group and for immersion group)

\begin{tabular}{||l|rrrrr|rrrrr|}
\hline & $S 1$ & $S 2$ & $S 3$ & $S 4$ & $A V$. & $I 5$ & $I 6$ & $I 7$ & $I 8$ & AV. \\
\hline Teacher/text & 84 & 96 & 94 & 84 & 89 & 85 & 71 & 81 & 97 & 83 \\
\hline Teach/text/student & 16 & 4 & 6 & 16 & 11 & 15 & 29 & 19 & 3 & 17 \\
\hline Students & 0 & 0 & 0 & 0 & 0 & 0 & 0 & 0 & 0 & 0 \\
\hline
\end{tabular}

As revealed in Table 4, differences between the two groups are also apparent with respect to the category of 'student modality'. Although both groups spent almost half their time (49\%) engaged in various combinations of listening, speaking, reading and writing, the submersion group spent considerably more time than the immersion group engaged primarily in listening (44\% vs. $24 \%)$, and less time engaged primarily in speaking ( $0 \%$ vs. $5 \%)$, in reading $(2 \%$ vs. $8 \%)$, and in writing ( $5 \%$ vs. $14 \%)$.

Table 4 Student modality (\% of total time for each class and average [AV.] for submersion group and for immersion group)

\begin{tabular}{||l|ccccc|ccccc|}
\hline & $S 1$ & $S 2$ & $S 3$ & $S 4$ & $A V$. & $I 5$ & $I 6$ & $I 7$ & $I 8$ & $A V$. \\
\hline Listening $^{\mathrm{a}}$ & 25 & 35 & 54 & 58 & 44 & 23 & 37 & 16 & 22 & 24 \\
\hline Speaking $^{\mathrm{a}}$ & 0 & 0 & 0 & 0 & 0 & 0 & 3 & 6 & 11 & 5 \\
\hline Reading $^{\mathrm{a}}$ & 6 & 1 & 0 & 2 & 2 & 12 & 4 & 6 & 12 & 8 \\
\hline Writing $^{\mathrm{a}}$ & 10 & 4 & 6 & 1 & 5 & 14 & 1 & 20 & 20 & 14 \\
\hline Combinations $^{-}$ & 59 & 60 & 40 & 39 & 49 & 51 & 55 & 52 & 35 & 49 \\
\hline
\end{tabular}

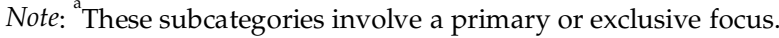


Table 5 displays results pertaining to 'materials type'. Submersion classes used primarily minimal text $53 \%$ of the time and extended text only $7 \%$ of the time (combinations of minimal and extended text occurred $9 \%$ of the time). Conversely, immersion classes used primarily extended text $43 \%$ of the time and minimal text for only $16 \%$ of the time (combinations accounted for the remaining $3 \%$ of the time). No materials were coded for $31 \%$ of the time in submersion classrooms and $38 \%$ of the time in immersion classrooms.

Table 5 Materials type (\% of total time for each class and average [AV.] for submersion group and for immersion group)

\begin{tabular}{|l|rrrrr|rrrrr||}
\hline & $S 1$ & $S 2$ & $S 3$ & $S 4$ & $A V$. & $I 5$ & $I 6$ & $I 7$ & $I 8$ & $A V$. \\
\hline Minimal & 61 & 57 & 49 & 46 & 53 & 23 & 1 & 11 & 31 & 16 \\
\hline Extended & 7 & 5 & 6 & 8 & 7 & 46 & 45 & 33 & 52 & 43 \\
\hline Minimal/extended & 5 & 14 & 2 & 18 & 9 & 0 & 11 & 0 & 0 & 3 \\
\hline Other & 27 & 24 & 43 & 28 & 31 & 31 & 43 & 56 & 17 & 38 \\
\hline
\end{tabular}

Profiles of two fairly distinct learning environments thus emerge from the COLT Part A analyses. The orientation in the submersion classrooms tends towards the analytic end of the continuum. Students in these classes were organised primarily in whole-class activities and also in some individual seat work but in no group work of any kind. The content in these classes, as determined almost consistently by the teacher and/or text, focused primarily on language form and only minimally on other topics. Students in these classes were often engaged in activities combining the four skills, but were engaged exclusively in listening activities for a considerable amount of time; no activities involved an exclusive focus on speaking and very few focused exclusively on reading or writing. The type of materials used in these classes entailed, for the most part, decontextualised language coded as minimal discourse. The high percentage of time spent on language form and use of minimal text clearly reflects the activities generally observed in these classrooms: for example, analysis of parts of speech, verb inflections, homonyms, sentence structure, agreement rules and dictation. Such activities resulted from the almost exclusive use in these classrooms of grammar textbooks, grammar workbooks and word lists.

On the other hand, the immersion classes proved to be more experiential in their overall orientation. For the most part, these classrooms were organised in whole-class activities, but sometimes this involved students presenting to students. The remainder of the time included a balance of individual seat-work and group activities. The content in these classes was almost equally divided between a focus on language and a focus on other topics, or included a combined focus on language and other topics (focus on other topics often included themes related to various stories or reference to subject matter such as social sciences). Classroom management accounted for one-tenth of the content focus in these classrooms; this may be a result of the greater variety of activities in these classrooms which required a renewal of procedures and some negotiation of tasks. As in the submersion classrooms, however, the content was determined primarily by the teacher and/or text, and not independently by students. The immersion students spent almost half their time, as did students in submersion 
classes, engaged in activities combining two or more language skills; they spent almost one-quarter of their time in activities with a primary focus on listening, and the remainder of the time in activities with a primary focus on either speaking, reading, or writing. The type of materials used in immersion classrooms involved, for the most part, extended discourse. Extended text was found in a variety of sources: for example, anthologies of short stories and legends, student-made reports, classified ads and recipes.

The profiles resulting from the COLT analyses concur with our qualitative data (i.e. field notes taken in the submersion classrooms and transcripts made from the audio-recordings of interaction in the immersion classrooms). To illustrate these two qualitatively distinct orientations, we have selected one lesson from S2 and one from I6 in which the teachers focus on a similar language feature, namely, homophones in French. In S2 the focus is on distinctions between $n i$ and $n^{\prime} y$, while in I6 the focus is on distinctions between peu, peux and peut. The description of the lesson in S2 has been extracted from the field notes; the description of I6 has been adapted from the transcripts.

\section{Teacher S2. 24 Janwary 1995}

Teacher S2 announces to the children, 'Guide Breton (author is Rita Breton), Cahier Breton et dictionnaire'. The children quickly get their three books out on their desks. They consist of the grammar textbook, the accompanying grammar workbook and their dictionaries. Teacher S2 brings me a copy of the grammar textbook to follow in. She then tells the children, 'Nous allons commencer dans le Guide Breton, page 152'.

I turn to the proper page to find a page all about the homophones $n^{\prime} y$ and $n i$. Teacher S2 sits at her desk and she reads the entire page, slowly for the children. There is not a sound as she reads and they follow in their own texts. Towards the bottom of the page there is a highlighted section which is entitled 'RETIENS' and contains the following information: 'J'écris $n$ ' $y$ quand ce $n^{\prime} y$ est utilisé dans une phrase négative avec pas, point, plus, jamais ou rien. Dans l'autre cas ... (similar explanation for proper use of $n i)^{\prime}$.

Once Teacher S2 has finished reading the page, she instructs, 'Fermez le livre'. They do as told. She then tells them to open their Cahier Breton but she does not tell them the page number. She tells them that they should be able to find the proper page that deals with the concept they have just been hearing about. A student raises her hand to indicate she has found it and Teacher S2 calls on her to give the page number for the class.

I look over the shoulder of the child nearest me to see a page of exercises all relating to the proper use of the homophones $n^{\prime} y$ and $n i$. The bulk of the page is devoted to a paragraph which is a cloze-type test in that blanks have been left in key areas where the child will have to determine if the proper word is $n^{\prime} y$ or $n i$. Teacher S2, sitting at her desk the whole time, reads the first sentence which does not have a blank. She then starts at the farthest corner away from her and asks a student to read the next sentence. He has a blank to fill in and he correctly spells the homophone that is required. One-by-one travelling across rows the children take a turn reading a 
sentence and providing the blank where required. Once the correct answer is given, the children are expected to fill in the blank on their page.

\section{Teacher $16 \cdot 7$ April 1995}

Students have their grammar exercise book, Stratégies, open and Teacher I6 asks them to turn to the next page which introduces the new theme of snow as well as the homophones peu, peux and peut. A student asks if they can begin the exercise, and Teacher I6 explains that they will simply discuss the homophones rather than complete the exercise. After two different students ask what page they should be at, several students provide the correct page number. Teacher I6 then writes peu, peux and peut on the chalkboard as she pronounces each word aloud. She asks students if they know what the words mean, and then focuses on peu by spelling it. Several students immediately reply, 'Pas beaucoup'. Teacher I6 then asks students to create sentences using the word peu. There is lots of enthusiastic participation as students suggest sentences such as 'Je parle un peu de français', 'On a peu d'argent', 'J'ai un peu peur des araignées', 'J'aime les chiens un peu'. After each proposal, Teacher 16 repeats the utterance and praises students for their correct contributions. She comments that peu is quite easy and then asks what peut means. One student replies that it's a verb. Teacher I6 asks what verb, to which students reply, 'Pouvoir'. She then asks what tense it is, to which a student replies, 'Troisième personne'. She repeats her question and other students correctly reply, 'Le présent'. She then conjugates pouvoir in the present as students join in as well. She asks what person peut is, to which students reply, in French, third person singular. She asks the same question about peux; and students reply correctly that it's both first and second person singular. One student spontaneously produces the phrase 'si tu peux' while another comments to Teacher I6 that peux can be replaced by capable. She concurs, juxtaposing 'je suis capable' and 'je peux' and comments on how easy these particular homophones are. A student asks if they are to complete the blanks in the exercise, and Teacher I6 replies negatively, commenting that it's very easy so students need not complete it; instead, she asks them to turn the page to the next section.

As indicated above, the two extracts were selected because of their similar focus on homophones. Such decontextualised grammar exercises were typical of the submersion classrooms, as reflected in the high percentage of minimal text used in these contexts. This type of exercise was less typical of the immersion classrooms. Had a more typical immersion lesson been selected, such as one focusing on other topics, the contrast would have been even more striking. This comparison is intended to illustrate that, even when the content focus is identical, the overall orientations are different: In the submersion class, rules are explained and then students one-by-one complete fill-in-the-blank exercises whereas, in the immersion class, students participate a great deal as they are asked to describe the homophonous distinctions and then to create their own illustrative examples. In the immersion class, therefore, discussion about language, some creativity, and even some student-initiated discourse, tended to replace the teacher-led drill observed in the submersion class. 


\section{Conclusion}

The present study aimed to answer the question, 'What are the similarities and differences in the type of language arts instruction received by L2 learners of French in the submersion context of the French-language schools and the immersion context of the English-language schools?' The foregoing results provide the following answer.

On the one hand, the language arts classes in the submersion context of the French-language schools (in which classes were designed for native speakers of French but comprised a large number of minority-language students learning French L2) were almost exclusively analytic in their approach to language teaching: the content focus was primarily on language form and most materials entailed only minimal discourse. On the other hand, the French immersion context in the English-language schools proved to be varied in its integration of analytic and experiential instructional options in language arts classes, including more variety in classroom organisation, content which focused on both language and other topics, and text which included more extended discourse.

The results revealing the experiential orientation in immersion classes confirm similar findings of previous studies (e.g. Allen et al., 1990; Dicks, 1992). Somewhat more surprising was the prevalence of such a predominantly analytic orientation in Grade 5 classrooms intended for native speakers of French - an orientation in sharp contrast with current trends in language arts instruction in the rest of North America. The 'whole language' approach, which minimises explicit language instruction and aims instead to integrate reading and writing skills for real communication across disciplines, appears to be completely absent from language arts instruction in these French-language schools. This leads to the speculation that these predominantly analytic classroom environments may not be providing, on their own, acquisition-rich environments for the minority-language students. Thus, the L2 learning needs of minority-language students may be at risk of not being fully addressed in these schools.

The data in the present study were exclusively process-oriented, consisting of almost 60 hours of classroom observations which were coded using COLT Part $\mathrm{A}$ in all eight classrooms. These data were further supplemented by transcripts of audio-recordings in the four immersion classrooms and by field notes in the four submersion classrooms. The absence of process-product data in the present study precludes any conclusions concerning the effects that the two contrasting orientations may have on L2 learning. However, we anticipate that the L2 development of learners in predominantly analytic classrooms will benefit from more experientially oriented intervention (see, for example, Montgomery \& Eisenstein, 1985; Savignon, 1972; Spada, 1987). In this vein, Fazio (in progress) has examined the effects of integrating a more experiential focus (i.e. journal writing) into the otherwise analytic classrooms in which the minority-language students find themselves.

There may be, however, overriding factors - external to the classroom environments - that the present study was not designed to analyse and that may affect, in significant ways, the L2 development of these two particular groups of learners. On the one hand, it may be argued that the broader context of the French-language schools and community offers the minority-language students 
an experiential L2 learning environment well beyond the language arts classroom. Indeed, we have interview data from school officials indicating that integration into this French-language community is considered to be very important for these minority-language students. The interviews also confirm, however, that the L1 of these minority-language students is generally perceived, by the school, as a hindrance to such integration (Fazio, 1996). On the other hand, immersion students, whose integration into the French-language community is not an expected outcome (Bibeau, 1982) and whose use of French remains limited outside the classroom (Genesee, 1987), are in fact encouraged to maintain their use of L1 within the broader community and even within the school, where English is part of the curriculum and is generally the language of social interaction and administrative activities.

Therefore, in addition to the contrasting instructional approaches found in their language arts classrooms, students from immersion contexts and those from submersion contexts are likely to experience their L2 (and L1) in considerably different ways outside the classroom as well. It may even be the case that the social context beyond classrooms has determined to some degree the pedagogical orientations discerned in the eight classrooms. That is, one might presume that learners with fewer opportunities for authentic L2 exposure outside the classroom (i.e. immersion students) require more exposure to communicative language use in the classroom whereas learners with more opportunities for authentic L2 exposure outside the classroom (i.e. minority-language students) require fewer opportunities for communicative language use in the classroom. However, it remains difficult to justify in this way an unequivocally analytic orientation in classrooms including minority-language students. Cummins (1989), for example, argues convincingly that minority-language students will benefit from, and indeed be empowered by, pedagogical intervention with an interactive/experiential orientation, whereas classrooms characterised by transmission models of pedagogy tend to 'disable' such students.

To conclude, we therefore return to the views of communicative language teaching as articulated, for example, by Stern $(1990,1992)$ and summarised at the beginning of this paper: If exclusively analytic classrooms are less propitious for L2 learning than classrooms integrating an experiential orientation in varying degrees, then the minority-language students in this study are in classroom environments that may be less conducive to L2 learning than those of the immersion students. With respect to L2 learning outcomes, however, the overall communicative orientation of language classrooms is unlikely to single-handedly determine success in a city such as Montreal; instead, classroom processes are bound to interact with external variables related to social context in ways that are worthy of further investigation.

\section{Correspondence}

Any correspondence should be directed to Roy Lyster (cxrl@musica.mcgill.ca) or Lucy Fazio (czfz@musica.mcgill.ca), Department of Second Language Education, Faculty of Education, McGill University, 3700 McTavish Street, Montreal, PQ, Canada H3A 1Y2 . 


\section{Note}

1. This research was funded by grants from the SocialSciences and Humanities Research Council of Canada (410-94-0783 and 752-94-1783) and from the Fonds pour la formation de chercheurs et l'aide à la recherche (97-NC-1409). We gratefully acknowledge the generous cooperation of the participating teachers and their students. We also thank Dawn Allen for aggregating the immersion data and Nina Spada for her helpful comments on an earlier version of this paper.

\section{References}

Allen, P., Fröhlich, M. and Spada, N. (1984) The Communicative Orientation of Language Teaching: An observation scheme. In J. Handscombe, R.A. Orem and B.P. Taylor (eds) On TESOL '83: The Question of Control (pp. 231-252). Washington, DC: TESOL.

Allen, P., Swain, M., Harley, B. and Cummins, J. (1990) Aspects of classroom treatment: Toward a more comprehensive view of second language education. In B. Harley, P. Allen, J. Cummins and M. Swain (eds) The Development of Second Language Proficiency (pp.57-81). Cambridge: Cambridge University Press.

Bibeau, G. (1982) L'éducation bilingue en Amérique du Nord. Montreal: Guérin éditeur limitée.

Cummins, J. (1989) Empowering Minority Students. Sacramento, CA: California Association for Bilingual Education.

Dicks, J. (1992) Analytic and experiential features of three French immersion programs: Early, middle and late. Canadian Modern Language Review 49,37-59.

Fazio, L. (1994) Mother tongue instruction and minority children's second-language performance. Journal of the Canadian Association of Applied Linguistics 16, 93-103.

Fazio, L. (1996) Minority language children acquiring a second language in first language learning environments. Paper presented at World Congress of Applied Linguistics (AILA 96), Jyväskylä, Finland.

Fazio, L. (in progress) The role of an experiential component in the analytic classrooms of minority language children. Doctoral dissertation, McGill University, Montreal, Canada.

Fröhlich, M., Spada, N., and Allen, P. (1985) Differences in the communicative orientation of L2 classrooms. TESOL Quarterly 19, 27-57.

Genesee, F. (1987) Learning Through Two Languages: Studies of Immersion and Bilingual Children. Cambridge, MA: Newbury House Publishers.

Leung, C. and Franson, C. (1989) The multilingual classroom: The case for minority language pupils. Journal of Multilingual and Multicultural Development 10, 461-472.

Lyster, R. (1998a) Recasts, repetition, and ambiguity in L2 classroom discourse. Studies in Second Language Acquisition 20, 51-81.

Lyster, R. (1998b) Negotiation of form, recasts, and explicit correction in relation to error type and learner repair in immersion classrooms. Language Learning 48, 193-218.

Lyster, R. (1998c)Immersion pedagogy and implications for language teaching. In J. Cenoz and F. Genesee (eds) Beyond Bilingualism: Multilingualism and Multilingual Education (pp. 64-95). Clevedon: Multilingual Matters.

Lyster, R. and Ranta, L. (1997) Corrective feedback and learner uptake: Negotiation of form in communicative classrooms. Studies in Second Language Acquisition 19, 37-66.

Montgomery, C. and Eisentein, M. (1985) Reality revisited: An experimental communicative course in ESL. TESOL Quarterly 19, 317-34.

Savignon, S. (1972) Communicative Competence: An Experiement in Foreign-language Teaching. Philadelphia, PA: Center for Curriculum Development.

Skutnabb-Kangas, T. (1991) Bilingualism or Not: The Education of Minorites. Clevedon: Multilingual Matters.

Spada, N. (1987) Relationships between instructional differences and learning outcomes: A process-product study of communicative language teaching. Applied Linguistics 8, 137-161.

Spada, N. and Fröhlich, M. (1995) COLT: Communicative Orientation of Language Teaching 
Observation Scheme: Coding Conventions and Applications. Sydney: National Centre for English Language Teaching and Research (NCELTR).

Stern, H.H. (1990) Analysis and experience as variables in second language pedagogy. In

B. Harley, P. Allen, J. Cummins and M. Swain (eds) The Development of Bilingual Proficiency (pp. 93-109). Cambridge: Cambridge University Press.

Stern, H.H. (1992) Issues and Options in Language Teaching (P. Allen and B. Harley, eds). Oxford: Oxford University Press.

Swain, M. and Johnson, K. (1997) Immersion education: A category within bilingual education. In R. Johnson and M. Swain (eds) Immersion Education: International Perspectives (pp. 1-16). Cambridge: Cambridge University Press. 